\title{
Aspergillus Colonization and Aflatoxin Contamination in Peanut Genotypes with Reduced Linoleic Acid Composition
}

\author{
C. Corley Holbrook, Research Geneticist, USDA-ARS, Tifton, GA 31793; David M. Wilson, Professor, Depart- \\ ment of Plant Pathology, University of Georgia, Tifton 31793; Michael E. Matheron, Professor, Department of \\ Plant Pathology, University of Arizona, Yuma 85364; John E. Hunter, Proctor \& Gamble Co., Cincinnati, OH \\ 45239, Retired; David A. Knauft, Associate Dean for Academic Affairs, University of Georgia, Athens 30602; and \\ Daniel W. Gorbet, Professor, Agronomy Department, University of Florida, Marianna 32446
}

\begin{abstract}
Holbrook, C. C., Wilson, D. M., Matheron, M. E., Hunter, J. E., Knauft, D. A., and Gorbet, D. W. 2000. Aspergillus colonization and aflatoxin contamination in peanut genotypes with reduced linoleic acid composition. Plant Dis. 84:148-150.

Aspergillus flavus and A. parasiticus can contaminate several agricultural crops with the toxic fungal metabolite aflatoxin. Previous research has indicated that resistance may be conferred by altering the fatty acid composition of these crops. Recently, peanut breeding lines with reduced linoleic acid content have been developed. The purpose of this study was to examine the effect of reduced linoleic acid composition on preharvest aflatoxin contamination of peanut. Seven breeding lines with relatively low linoleic acid and two check genotypes were grown in a randomized complete block design with 10 replicates for 4 years in Georgia and for 3 years in Arizona. The plots were inoculated with a mixture of A. flavus and A. parasiticus about 60 days after planting and subjected to drought and heat stress for the 40 days immediately preceding harvest. Differences were observed in only one environment. Low linoleic acid composition had no measurable effect on preharvest aflatoxin contamination in peanut when data were combined across years and locations. Products of the lipoxygenase pathway that have been shown to affect aflatoxin biosynthesis in vitro may not be present in sufficient quantities in peanut.
\end{abstract}

Aspergillus flavus and A. parasiticus can colonize seed of several agricultural crops (3). This can result in the contamination of the edible yield from these crops with the toxic fungal metabolite aflatoxin. The development of resistant crops would be a powerful tool in reducing this problem. Research has indicated that resistance may be possible by altering the fatty acid composition of these crops. Several in vitro studies have shown that fatty acid composition might directly or indirectly affect aflatoxin biosynthesis $(2,4,5,12)$.

Fabbri et al. (5) proposed that aflatoxin production is increased by lipoperoxides of polyunsaturated fatty acids. Passi et al. (12) observed that the addition of linoleic acid hydroperoxides to in vitro $A$. parasiticus cultures enhanced the aflatoxin output by about 30 times after 6 days of incubation, and by about 250 times after 12 days of incubation. The amount of fungal growth was not affected.

Others have observed an inhibitory ef-

Corresponding author: C. C. Holbrook

E-mail: holbrook@tifton.cpes.peachnet.edu

Accepted for publication 8 October 1999.

Publication no. D-1999-1115-01R

This article is in the public domain and not copyrightable. It may be freely reprinted with customary crediting of the source. The American Phytopathological Society, 2000. fect of hydroperoxides of linoleic acid. Doehlert et al. (4) found that if soybean homogenates were supplemented with high amounts of either lipase, linoleic, or linolenic acid, volatiles that inhibit fungal spore germination were generated. Oleic acid had no effect compared with untreated homogenates. Hexanal, a product of the lipoxygenase pathway with known antifungal activity, was the major volatile generated from lipase-treated homogenates. Burrow et al. (2) observed that $13 S$ hydroperoxy linoleic acid significantly decreased aflatoxin production when introduced into growth media at 24-h intervals.

A peanut line has been identified with $2 \%$ linoleic acid (11). The line is more saturated than standard cultivars, which average $25 \%$ linoleic acid. The low linoleic acid trait has been incorporated into highyielding, agronomically acceptable breeding lines (9) and cultivars (7).

If feasible, altering fatty acid composition would be an attractive approach to managing aflatoxin contamination in peanut. Fatty acid composition is much cheaper to measure than aflatoxin contamination, it is subject to much less environmental variability, and it is simply inherited (10). The objective of this study was to examine seven breeding lines with relatively low linoleic acid and two check genotypes under drought and heat stress conditions to determine if altered fatty acid composition would influence aflatoxin contamination of peanut.

\section{MATERIALS AND METHODS}

Seven peanut breeding lines were selected for evaluation of Aspergillus colonization and preharvest aflatoxin contamination based on their low linoleic acid composition. The cultivar Florunner and the germ plasm line Tifton 8 were included as checks. Seeds were planted in Yuma, Arizona, on 25 May 1993, 4 May 1994, and 6 May 1996 in double-row plots (1.5 $\times 1.8 \mathrm{~m}$ ) at four seeds per $30-\mathrm{cm}$ linear row. Genotypes were arranged in a randomized complete block design with 10 replicates in each trial. All plants were maintained with adequate moisture, using flood irrigation.

The same genotypes were evaluated at the Coastal Plain Experiment Station Gibbs Farm in Tift County, Georgia. Genotypes were planted on 21 June 1993, 28 April 1994, 5 May 1995, and 17 May 1996 in single-row plots, $1.5 \mathrm{~m}$ long, at four seeds per $30-\mathrm{cm}$ linear row in a randomized complete block design with 10 replicates. Plants were maintained with standard cultural practices and irrigation.

Inoculum of A. flavus (NRRL 3357) and A. parasiticus (NRRL 2999) was prepared by the organic-matrix method (16) and introduced into test plots to ensure the presence of sufficient aflatoxin-producing fungi in the peanut pod zone. Conidia of $A$. flavus or $A$. parasiticus, each from a $10-$ day culture, were suspended in sterile distilled water (10 ml per $114 \mathrm{~g}$ of corn) and used to inoculate sterile moisture-equilibrated (25\% moisture) cracked corn. The corn was incubated at 25 to $30^{\circ} \mathrm{C}$ for 3 days.

Each double-row plot in Arizona was treated with $57 \mathrm{~g}$ of corn infested with $A$. flavus and $57 \mathrm{~g}$ of corn infested with $A$. parasiticus on 26 July 1993, 18 July 1994, and 15 July 1996. Drought stress was induced by terminating flood irrigation on 17 August 1993, 14 August 1994, and 9 August 1996. Thereafter, irrigation was applied with subsurface perforated tubing $35 \mathrm{~cm}$ beneath the rows. Four hours of drip irrigation was applied when plants showed significant symptoms of drought stress (8). Pods were harvested on 14 October 1993, 29 September 1994, and 10 October 1996, 
dried, and sent to the Coastal Plain Experiment Station for processing.

Each single-row plot in Georgia was inoculated with $28 \mathrm{~g}$ of corn infested with $A$. flavus and $28 \mathrm{~g}$ of corn infested with $A$. parasiticus on 25 August 1993, 30 June 1994, 5 July 1995, and 16 July 1996. Drought and heat stress were induced by covering the entire test area with a mobile greenhouse (Atlas Greenhouse System Inc., Alapaha, GA) on 20 September 1993, 1 August 1994, 8 August 1995, and 19 August 1996. Pods were dug 15 November 1993, 24 September 1994, 28 September 1995, and 14 October 1996, hand-picked from the plant, and dried.

Seeds from undamaged pods were stored at $-20^{\circ} \mathrm{C}$ until processing to prevent postharvest accumulation of aflatoxin. Peanuts were shelled with a Penco (Peerless Engineering Company, Chula, GA) peanut sheller and ground in a household food processor for $1 \mathrm{~min}$. Aflatoxin concentration was measured on a $100-\mathrm{g}$ subsample by the immunoaffinity column fluorometer method (15). The fluorometer was calibrated from 0 to $400 \mathrm{ng} / \mathrm{g}$. If the initial analysis indicated a concentration above $400 \mathrm{ng} / \mathrm{g}$, the sample extract was diluted $1: 10$ and reanalyzed. If the reanalyzed sample indicated a concentration above 4,000 ng/g, an additional 1:10 dilution and analysis was performed.

Fifty pods were surface-disinfested with $0.5 \%$ sodium hypochlorite and aseptically shelled for analysis of infection by species of the A. flavus group and A. niger. Halfshells (100) and seeds (100) were placed in petri dishes containing malt extract agar containing $10 \% \mathrm{NaCl}$ by weight and incubated at $30^{\circ} \mathrm{C}$. After 7 days, the material was examined for green conidial heads of Aspergillus spp. of the A. flavus group and black conidial heads of $A$. niger to determine the percent infection.

Data were analyzed by the general linear model procedure of SAS (SAS Institute, Cary, NC), and genotypic means were compared by Fisher's protected least significant difference (LSD). Unless other- wise stated, all differences referred to in the test were significant at $P \leq 0.05$.

\section{RESULTS AND DISCUSSION}

All of the low linoleic peanut lines had less preharvest aflatoxin contamination than Florunner when tested in Arizona in 1993 (Table 1). Five of these lines also had numerically less aflatoxin contamination than Florunner when tested in Georgia in 1993, but these differences were not significant. Aflatoxin contamination levels in both locations for 1994 were low, and none of the entries showed a difference in aflatoxin levels compared with Florunner. Higher levels of contamination were observed in 1995 and 1996, but no significant differences in aflatoxin contamination were observed.

Four additional breeding lines with reduced linoleic acid were examined in a separate set of tests in Arizona and Tifton in 1994 and 1995 (data not presented). These tests also showed no significant effect of reduced linoleic acid composi-

Table 1. Preharvest aflatoxin contamination in peanut genotypes when grown under drought stressed conditions in Georgia and Arizona

\begin{tabular}{|c|c|c|c|c|c|c|c|c|}
\hline \multirow[b]{3}{*}{ Entry } & \multicolumn{8}{|c|}{ Aflatoxin contamination $(\mathrm{ng} / \mathrm{g})^{\mathrm{a}}$} \\
\hline & \multicolumn{4}{|c|}{ Georgia } & \multicolumn{3}{|c|}{ Arizona } & \multirow[b]{2}{*}{ Mean } \\
\hline & 1993 & 1994 & 1995 & 1996 & 1993 & 1994 & 1996 & \\
\hline $\mathrm{F} 1250^{\mathrm{b}}$ & 4 & 24 & 2,800 & 958 & 653 & 12 & 18,559 & 3,447 \\
\hline Florunner & 77 & 10 & 4,054 & 468 & 5,968 & 16 & 14,027 & 3,028 \\
\hline $\mathrm{F} 1341^{\mathrm{b}}$ & 144 & 11 & 2,592 & 273 & 333 & 18 & 13,071 & 2,503 \\
\hline $\mathrm{F} 1344^{\mathrm{b}}$ & 44 & 31 & 1,040 & 1,206 & 46 & 12 & 12,727 & 2,124 \\
\hline Tifton 8 & 8 & 47 & 915 & 42 & 91 & 10 & 12,195 & 2,047 \\
\hline $\mathrm{F} 1348^{\mathrm{b}}$ & 12 & 15 & 3,985 & 932 & 210 & 327 & 9,391 & 1,976 \\
\hline $\mathrm{F} 1334^{\mathrm{b}}$ & 11 & 399 & 2,419 & 1,455 & 186 & 10 & 10,082 & 1,972 \\
\hline $\mathrm{F} 1316^{\mathrm{b}}$ & 203 & 9 & 2,737 & 397 & 64 & 12 & 5,895 & 1,310 \\
\hline $\mathrm{F} 1315^{\mathrm{b}}$ & 20 & 13 & 2,504 & 1,221 & 88 & 33 & 4,136 & 1,173 \\
\hline $\operatorname{LSD}^{c}(0.05)$ & $\mathrm{NS}^{\mathrm{d}}$ & 167 & NS & NS & 2,656 & NS & NS & NS \\
\hline
\end{tabular}

a Each value is the mean of 10 replicates.

${ }^{\mathrm{b}}$ Genotypes with low linoleic acid content.

c Least significant difference.

d Entry effect in ANOVA was not significant.

Table 2. Aspergillus colonization in seeds and shells of peanut genotypes when grown under drought stressed conditions in Georgia (1993 and 1994) and Arizona (1994)

\begin{tabular}{|c|c|c|c|c|c|c|c|c|}
\hline \multirow[b]{4}{*}{ Entry } & \multicolumn{8}{|c|}{ Aspergillus colonization (\%) } \\
\hline & \multicolumn{4}{|c|}{ Georgia } & \multicolumn{4}{|c|}{ Arizona } \\
\hline & \multicolumn{2}{|c|}{ Seeds $^{\mathbf{a}}$} & \multicolumn{2}{|c|}{ Shell $^{b}$} & \multicolumn{2}{|c|}{ Seeds $^{\mathbf{a}}$} & \multicolumn{2}{|c|}{ Shell $^{\text {b }}$} \\
\hline & A. flavus & A. niger & A. flavus & A. niger & A. flavus & A. niger & A. flavus & A. niger \\
\hline F1250 & 1 & 6 & 13 & 22 & 7 & 0 & 52 & 17 \\
\hline F1315 & 2 & 1 & 14 & 8 & 12 & 2 & 50 & 10 \\
\hline F1316 & 3 & 4 & 13 & 22 & 7 & 0 & 55 & 20 \\
\hline F1334 & 5 & 1 & 16 & 8 & 1 & 0 & 35 & 14 \\
\hline F1341 & 1 & 2 & 8 & 10 & 7 & 1 & 59 & 24 \\
\hline F1344 & 2 & 0 & 13 & 11 & 4 & 2 & 42 & 29 \\
\hline F1348 & 1 & 2 & 9 & 14 & 6 & 1 & 55 & 22 \\
\hline Florunner & 3 & 2 & 9 & 10 & 12 & 0 & 66 & 18 \\
\hline Tifton 8 & 5 & 2 & 29 & 16 & 15 & 0 & 64 & 18 \\
\hline $\operatorname{LSD}^{\mathrm{c}}(0.05)$ & $\mathrm{NS}^{\mathrm{d}}$ & 3 & 10 & 10 & 8 & NS & 22 & NS \\
\hline
\end{tabular}

a Each value is the mean percentage of seeds colonized, determined by plating a 100-seed subsample from 10 replicates for 2 years (Georgia) or 1 year (Arizona).

${ }^{\mathrm{b}}$ Each value is the mean percentage of half-shells colonized, determined by plating a 100-half-shelf subsample from 10 replicates for 2 years (Georgia) or 1 year (Arizona).

${ }^{c}$ Least significant difference.

${ }^{d}$ Entry effect in analysis of variance was not significant. 
tion on preharvest aflatoxin contamination.

When the data are viewed in total, there appears to be no effect of low linoleic acid content on preharvest aflatoxin contamination in peanut. The significant differences observed in Arizona in 1993 may have been due to the large inherent variability of aflatoxin contamination in peanut. Three of the 10 replicates of Florunner had much higher aflatoxin contamination than all other plots in this test.

Several in vitro studies have shown that fatty acid composition might directly or indirectly affect aflatoxin biosynthesis $(2,4,5,12)$. In contrast, we observed no effect of altered fatty acid composition on preharvest aflatoxin contamination in peanut. The previously observed effects of fatty acid composition on aflatoxin biosynthesis appeared to be related to substances formed during the oxidation of polyunsaturated fatty acids. The lack of significant differences in the present study may be due to a low level of lipid oxidation in peanut prior to harvest regardless of varying endogenous levels of linoleic acid. However, other degradatory enzymes (e.g., lipase) are probably not limiting, since it has been reported that A. flavus secretes enzymes with abundant lipase activity when invading oil-seed hosts (13). Gardner et al. (6) postulated that lipase secreted by an invading fungus would trigger the lipoxygenase pathway in soybean, resulting in the generation of volatile aldehydes.

Doehlert et al. (4) showed that if soybean homogenates were supplemented with high amounts of lipase, volatiles were generated that inhibited fungal spore germination. Headspace analysis indicated that hexanal, a product of the lipoxygenase pathway with known antifungal activity, was the major volatile generated. The lipoxygenase (LOX I) isozymes in soybean react with linoleic acid to form the 13hydroperoxide from which hexanal would be generated by the action of hydroperoxide lyase.

The lack of an effect of reduced linoleic fatty acid composition on preharvest aflatoxin contamination in peanut may be due to a different lipoxygenase pathway in peanut. Burrow et al. (2) demonstrated that the 13-hydroperoxy linoleic acid significantly decreased aflatoxin production, whereas 9-hydroperoxy linoleic acid (formed by LOX II isozymes) did not decrease aflatoxin production. Sung and Jeng (14) observed that LOX II activity was much higher than the activity of LOX I in accelerated aged peanut seed. For whatever reason, reducing linoleic fatty acid composition does not appear to be a viable approach to reducing preharvest aflatoxin in peanut.

Conflicting information is in the literature on the relative susceptibility of the two checks included in this study. Wilson et al. (17) reported that the germ plasm line Tifton 8 had some resistance to preharvest aflatoxin contamination. However, Anderson et al. (1) did not observe a reduction in PAC in Tifton 8 compared with Florunner. The present study supports the findings of Anderson et al. (1).

None of the low linoleic peanut lines exhibited different levels of colonization of shells or seeds by A. flavus group fungi compared with Florunner when tested in Georgia (Table 2). All these genotypes were also at least as susceptible as Florunner to colonization of shells and seeds by A. niger in the Georgia tests.

The patterns observed in colonization of shells or seeds in Georgia were not observed when this material was tested in Arizona (Table 2). Two of the low linoleic lines (F1334 and F1344) exhibited significantly less colonization of seeds and shells by A. flavus. This may be due to differences in environmental variables (temperature and humidity) between the two locations, or to a difference in fungal population dynamics between the two locations. Wilson et al. (18) observed poor survival of A. parasiticus in Arizona. The developing pods in the Georgia tests were challenged by a mixture of A. flavus and A. parasiticus, whereas those in the Arizona test were challenged primarily by A. flavus.

\section{ACKNOWLEDGMENTS}

This work was supported in part by a grant from the Peanut Foundation. We thank J. Day, B. Evans, V. Hogan, D. Mauldin, and B. Tyler for their contributions and technical support.

\section{LITERATURE CITED}

1. Anderson, W. F., Holbrook, C. C., Wilson, D. M., and Matheron, M. E. 1995. Evaluation of preharvest aflatoxin contamination in several potentially resistant peanut genotypes. Peanut Sci. 22:29-32.

2. Burrow, G. B., Nesbitt, T. C., Dunlap, J., and Keller, N. P. 1997. Seed lipoxygenase products modulate Aspergillus mycotoxin biosynthesis. Mol. Plant-Microbe Interact. 10:380-387.

3. CAST. 1989. Mycotoxins: Economic and health risks. Task force rep. 116. Council of Agricultural Science and Technology, Ames, IA.
4. Doehlert, D. C., Wicklow, D. T., and Gardner, H. W. 1993. Evidence implicating the lipoxygenase pathway in providing resistance to soybeans against Aspergillus flavus. Phytopathology 83:1473-1477.

5. Fabbri, A. A., Fanelli, C., Panfili, G., Passi, S., and Fasella, P. 1983. Lipoperoxidation and aflatoxin biosynthesis by Aspergillus parasiticus and A. flavus. J. Gen. Microbiol. 129:3447-3452.

6. Gardner, H. W., Dornbos, D. L., and Desjardins, A. E. 1990. Hexanal, trans-2-hexenal and trans-2-nonenal inhibit soybean, Glycine max, seed germination. J. Agric. Food Chem. 38:1316-1320.

7. Gorbet, D. W., and Knauft, D. A. 1997. Registration of 'Sun Oleic 95R' peanut. Crop Sci. 37:1392.

8. Holbrook, C. C., Matheron, M. E., Wilson, D. M., Anderson, W. F., Will, M. E., and Norden, A. J. 1994. Development of a large-scale field system for screening peanut for resistance to preharvest aflatoxin contamination. Peanut Sci. 21:20-22.

9. Knauft, D. A., Moore, K. M., and Gorbet, D. W. 1993. Further studies on the inheritance of fatty acid composition in peanut. Peanut Sci. 20:74-76.

10. Moore, K. M., and Knauft, D. A. 1989. The inheritance of high oleic acid in peanut. J. Hered. 80:252-253.

11. Norden, A. J., Gorbet, D. W., Knauft, D. A. and Young, C. T. 1987. Variability in oil quality among peanut genotypes in the Florida breeding program. Peanut Sci. 14:7-11.

12. Passi, S., Nazzaro-Porro, M., Fannelli, C., Fabbri, A. A., and Fasella, P. 1984. Role of lipoperoxidation in aflatoxin production. Appl. Microbiol. Biotechnol. 19:186-190.

13. Raper, K. B., and Fennell, D. I. 1965. Aspergillus flavus group. Pages 393-394 in: The Genus Aspergillus. Williams \& Wilkins Co., Baltimore, MD

14. Sung, J. M., and Jeng, T. L. 1994. Lipid peroxidation and peroxide-scavenging enzymes associated with accelerated aging of peanut seed. Physiol. Plant. 91:51-55.

15. Trucksess, M. W., Stack, M. E., Nesheim, S., Page, S. W., Albert, R. H., Hansen, T. J., and Donahue, K. F. 1991. Immunoaffinity column coupled with solution fluorometry or liquid chromatography postcolumn derivitization for determination of aflatoxins in corn, peanuts, and peanut butter: Collaborative study. J. Assoc. Off. Anal. Chem. 74:81-88.

16. Will, M. E., Holbrook, C. C., and Wilson, D. M. 1994. Evaluation of field inoculation techniques for screening peanut genotypes for reaction to preharvest $A$. flavus group infection and aflatoxin contamination. Peanut Sci. 21:122-125.

17. Wilson, D. M., Branch, W. D., Beaver, R. W., and Maw, B. W. 1990. Screening peanut genotypes for resistance to aflatoxin accumulation. (Abstr.) Proc. Am. Peanut Res. Educ. Soc. 22:33

18. Wilson, D. M., Holbrook, C. C., and Matheron, M. E. 1996. Aspergillus flavus and A. parasiticus used as peanut plot inoculum to study preharvest aflatoxin contamination. (Abstr.) Proc. Am. Peanut Res. Educ. Soc. 28:30. 